\title{
PENGUJIAN TECHNOLOGY ACCEPTANCE MODEL PADA MOBILE BANKING SEBAGAI DETERMINAN PERFORMA UMKM DI KOTA MAKASSAR
}

\author{
Syarief Dienan Yahya*1, Harry Yulianto ${ }^{2}$ \\ Dosen Program Studi Manajemen STIE YPUP Makasssar \\ E-mail: "1 dienanyahya@gmail.com, ${ }^{2}$ harryyulianto.stieypup@gmail.com
}

\begin{abstract}
Technology adoption plays an important role in competing and creating opportunities in business nowadays. Mobile Banking has changed the way the banking industry and business interact. Mobile Banking is an alternative business strategy for businesses to survive in an increasingly competitive business in today's digital era. This study will focus on adopting Mobile Banking technology and its role to improve the performance of Micro, Small and Medium Enterprises (MSMEs) by adapting the Technology Acceptance Model concept using several indicators from various previous studies which consist of Perceived Ease of Use, Perceived Usefulness, Social Norms, Perceived Risk, Relative Advantages, Personal Innovativeness and Cost as indicators. The study involved 278 Micro, Small and Medium Enterprises (MSMEs) in Makassar City by using a self-administered questionnaire, which was determined using the Purposive Sampling method. The result shows that simultaneously all indicators of the construct of Technology Acceptance Model had a positive and significant influence on the performance of Micro, Small and Medium Enterprises (MSMEs) in Makassar City. Furthermore, partially each indicator shows a positive and significant influence and personal innovativeness is the most dominant indicator in influencing Micro, Small and Medium Enterprises (MSMEs) performance. The findings of this study are expected to enrich the study related to the topic of Technology Acceptance Model in Mobile Banking and its relationship to improving the performance of Micro, Small and Medium Enterprises (MSMES).
\end{abstract}

Keywords: Technology Acceptance Model, Mobile Banking, Mobile Money, Digital Banking, Usaha Mikro Kecil Menengah, Kota Makassar

\section{PENDAHULUAN}

Perkembangan teknologi digital dalam beberapa tahun terakhir telah mengubah cara industri perbankan dalam memberikan pelayananan kepada nasabah. Beragam inovasi pada industri perbankan terus dikembangkan dalam upaya memberikan kemudahan bagi nasabah, termasuk layanan Mobile Banking. Mobile Banking telah mengubah cara konvensional nasabah dalam menggunakan layanan perbankan. Hal ini didukung dengan kebutuhan dan tuntutan sosial masyarakat saat ini yang semakin mengendepankan efektifitas dan efisiensi. Perkembangan tersebut sangat berpotensi meningkat seiring dengan perkembangan layanan perbankan yang semakin mengarah pada Digital Banking. Selain itu, perkembangan bisnis daring yang semakin marak ditopang dengan perkembangan kemajuan ponsel pintar (Smartphone) memberikan andil dalam perkembangan layanan teknologi Mobile Banking.

Kemajuan teknologi ponsel pintar (Smartphone) telah menginisiasi berbagai pelayanan dan fasilitas perbankan yang ditawarkan kepada nasabah. Salah satu fasilitas perbankan yang berkembang pesat seiring dengan perkembangan teknologi ponsel pintar (Smartphone) adalah Mobile Banking. Perkembangan Mobile Banking terbilang cukup pesat. Kehadiran layanan Mobile Banking semakin berkembang seiring dengan 
kemampuanya menjawab kebutuhan masyarakat modern yang dinamis dan mengedepankan pada mobilitas. Mobile Banking memberikan kemudahan layanan perbankan dan keuangan kepada nasabah dengan melalui perangkat ponsel pintar (Smartphone). Mobile Banking mampu memberikan keleluasaan dan kepraktisan nasabah dalam bertransaksi. Kebutuhan transaksi yang paling mendasar berupa cek saldo, pembayaran tagihan, transfer uang, maupun layanan keuangan lainnya bisa dilakukan dengan hanya menekan tombol-tombol di ponsel. Transaksi pun bisa dapat dilakukan di mana saja dan kapan saja sejauh jaringan tersedia.

Usaha Mikro, Kecil, dan Menengah (UMKM) merupakan salah satu sektor yang berperan penting dalam pembangunan perekonomian Indonesia. Usaha Mikro, Kecil, dan Menengah (UMKM) memiliki proporsi paling dominan dari total keseluruhan pelaku usaha di Indonesia. Selain itu, digitalisasi sektor Usaha Mikro Kecil Menengah (UMKM) menjadi salah satu fokus pembangunan perekonomian pemerintah Indonesia saat ini. Upaya digitalisasi Usaha Mikro, Kecil, dan Menengah (UMKM) diharapkan dalam menstimulus performa Usaha Mikro, Kecil, dan Menengah (UMKM) agar sejalan dengan perkembangan teknologi informasi yang semakin pesat dalam persaingan pasar yang kian terbuka.

Kehadiran Mobile Banking sebagai sebuah inovasi dalam industri perbankan yang telah mengubah cara pelaku usaha Usaha Mikro Kecil dan Menengah (UMKM) menggunakan fasilitas perbankan, diharapkan dapat mendukung pengembangan Usaha Mikro Kecil dan Menengah (UMKM) yang menjadi penopang ekonomi masyarakat dan juga menjadi penggerak pembangunan ekonomi bagi daerah, baik dari segi pendapatan asli daerah maupun perekonomian Indonesia secara umum.
Usaha Mikro, Kecil, dan Menengah (UMKM) merupakan salah satu sektor yang berperan penting dalam pembangunan perekonomian Indonesia. Usaha Mikro, Kecil, dan Menengah (UMKM) memiliki proporsi paling dominan dari total keseluruhan pelaku usaha di Indonesia (Lembaga Pengembangan Perbankan Indonesia, 2015). Selain itu digitalisasi sektor Usaha Mikro Kecil Menengah (UMKM) menjadi salah satu fokus pembangunan perekonomian pemerintah indonesia saat ini. Upaya digitalisasi Usaha Mikro, Kecil, dan Menengah (UMKM) diharapkan dalam menstimulus performa UMKM agar sejalan dengan perkembangan teknologi informasi yang semakin pesat dalam persaingan pasar yang kian terbuka.

Usaha Mikro, Kecil dan Menengah (UMKM) sebagai penyangga perekonomian kerakyatan dapat memberikan dampak langsung pada kehidupan ekonomi masyarakat kelas bawah. Usaha Mikro, Kecil dan Menengah (UMKM) mempunyai peran penting dan strategis dalam pembangunan ekonomi nasional. Selain berperan dalam pertumbuhan ekono mi dan penyerapan tenaga kerja, UMKM juga berperan dalam mendistribusikan hasil-hasil pembangunan (Lembaga Pengembangan Perbankan Indonesia, 2015).

Usaha Mikro, Kecil dan Menengah (UMKM) mampu menyerap tenaga kerja sekitar 97\% dari seluruh tenaga kerja nasional dan berkontribusi terhadap Produk Domestik Bruto (PDB) sekitar 57\%, Usaha Mikro, Kecil dan Menengah juga telah terbukti tidak terpengaruh terhadap krisis. Ketika krisis menerpa pada periode tahun 1997-1998, hanya sektor UMKM yang mampu tetap berdiri kokoh (Lembaga Pengembangan Perbankan Indonesia, 2015). Petumbuhan Usaha Mikro, Kecil dan Menengah di kota Makassar juga mengalami peningkatan yang signifikan dalam beberapa tahun terakhir. Dinas Koperasi Kota Makassar mencatat 
pertumbuhan UMKM sejak tahun 2016 hingga 2018 sebanyak 16.428 UMKM baru yang tersebar di 15 Kecamatan di Kota Makassar (Hamzah, 2018).

Mobile Banking diharapkan dapat menjadi alternatif strategi bisnis bagi pelaku Usaha Menengah Kecil Mikro (UMKM) untuk dapat bertahan pada dunia usaha yang semakin kompetitif di era digital. Selain itu, masih minimnya penelitian tentang konsep Technology Acceptance Model pada Mobile Banking sebagai Determinan performa UMKM membuat topik ini menjadi semakin menarik untuk diteliti. Penelitian ini diharapakan dapat memperkaya kajian terkait topik Technology Acceptance Model pada Mobile Banking dan hubungannya terhadap peningkatan performa UMKM, sehingga dapat menjadi referensi bagi berbagai pihak dimasa yang akan datang.

\section{TINJAUAN PUSTAKA}

\section{Entrepreneurship and Innovation Theory}

Teori Kewirausahaan dan Inovasi (Entrepreneurship and Innovation Theory) pertama kali diperkenalkan dan dikembangkan oleh Joseph Alois Schumpeter, teori ini berfokus membahas pada peranan inovasi terhadap kewirausahaan, ekonomi, dan perubahan sosial (Mararo dan Ngahu, 2017). Schumpeter berpendapat bahwa siapa pun yang mencari keuntungan harus berinovasi, inovasi dianggap sebagai faktor penting penggerak daya saing dan dinamika ekonomi (Śledzik, 2013). Inovasi hadir sebagai peluang, di mana pengusaha dapat menciptakan produk baru, metode produksi baru, sumber pasokan baru, eksploitasi pasar baru, dan menemukan cara-cara baru dalam mengelola bisnis (Śledzik, 2013). Pada konteks penelitian ini, penggunaan Mobile Banking memberikan peluang bagi pelaku Usaha Menengah Kecil Mikro (UMKM) untuk eksplorasi cara-cara baru dalam mengelola bisnis.

\section{Mobile Banking}

Mobile Banking merupakan layanan yang memungkinkan nasabah bank melakukan transaksi perbankan melalui ponsel atau Smartphone. Layanan Mobile Banking dapat digunakan dengan menggunakan menu yang sudah tersedia pada aplikasi yang dapat diunduh dan diinstal oleh nasabah. Mobile Banking menawarkan kemudahan jika dibandingkan dengan SMS banking karena nasabah tidak perlu mengingat format pesan SMS yang akan dikirimkan ke bank dan juga nomor tujuan SMS banking (Otoritas Jasa Keuangan, 2015). Fitur-fitur layanan Mobile Banking antara lain layanan informasi (saldo, mutasi rekening, tagihan kartu kredit, suku bunga, dan lokasi cabang/ATM terdekat) dan layanan transaksi, seperti transfer, pembayaran tagihan (listrik, air, pajak, kartu kredit, asuransi, internet pembelian pulsa, tiket, dan berbagai fitur lainnya (Otoritas Jasa Keuangan, 2015).

\section{Usaha Mikro, Kecil, dan Menengah}

Di Indonesia, Undang-Undang yang mengatur tentang Usaha Mikro, Kecil, dan Menengah (UMKM) adalah UndangUndang Nomor 20 Tahun 2008. Dalam undang-undang tersebut UMKM dijelaskan sebagai perusahaan kecil yang dimiliki dan dikelola oleh seseorang atau dimiliki oleh sekelompok kecil orang dengan jumlah kekayaan dan pendapatan tertentu (Lembaga Pengembangan Perbankan Indonesia, 2015). Dalam perspektif usaha, Usaha Menengah Kecil Mikro (UMKM) diklasifikasikan dalam empat kelompok yaitu: a) UMKM Mikro adalah para UMKM dengan kemampuan sifat pengrajin, b) UMKM sektor informal, contohnya pedagang kaki lima, namun kurang memiliki jiwa kewirausahaan untuk mengembangkan usahanya. c) 
Usaha Kecil Dinamis adalah kelompok UMKM yang mampu berwirausaha dengan menjalin kerjasama (menerima pekerjaan sub kontrak) dan ekspor. d) Fast Moving Enterprise adalah UMKM yang mempunyai kewirausahaan yang cakap dan telah siap bertransformasi menjadi usaha besar (Lembaga Pengembangan Perbankan Indonesia, 2015).

\section{Technology Acceptance Model}

Terdapat beberapa model yang berkembang dan digunakan dalam membahas pengadopsian sebuah teknologi, salah satunya adalah Technology Acceptance Model. Konsep Technology Acceptance Model merupakan salah satu teori dan dikembangkan oleh Davis di tahun 1989 yang adaptasi dari Theory of Reasoned Action yang diperkenalkan oleh Ajzen dan Fishbein pada tahun 1980. Model ini awalnya dirancang untuk memprediksi penerimaan pengguna Teknologi Informasi dan penggunaanya dalam sebuah organisasi (Lule et al, 2012). Technology Acceptance Model kemudian berkembang menjadi sebuah teori yang menjelaskan persepsi pengguna terhadap teknologi, persepsi pengguna tersebut akan berpengaruh terhadap minat menggunakan teknologi tersebut (Lule et al, 2012).

Technology Acceptance Model dalam penelitian ini diadopsi dari penelitian sebelumnya yang terdiri dari konstruk Perceived Ease of Use, Perceived Usefulness, Social Norms, Perceived Risk, Relative Advantages, Personal Innovativeness dan Cost (Chitungo dan Munongo, 2013). Perceived ease of use merupakan sebuah kondisi dimana seseorang percaya bahwa penggunaan sistem tertentu, mampu meringankan usaha seseorang dalam mengerjakan sesuatu (Chitungo dan Munongo, 2013). Perceived Usefulness merupakan suatu kondisi dimana seseorang percaya bahwa pemakaian suatu sistem tertentu akan dapat meningkatkan kinerjanya (Chitungo dan Munongo,
2013). Social Norms didefinisikan sebagai kondisi dimana penggunaan sebuah inovasi akan meningkatkan status atau derajat seseorang dalam sistem sosial (Reich dan Izak, 2000), konstruk pengaruh sosial tidak dapat diabaikan dalam model adopsi inovasi apa pun (Pedersen dan Ling, 2002). Perceived Risk merupakan pandangan subjektif pengguna tentang kerugian yang dirasakan dari penggunaan sistem tertentu (Fadare, 2016). Relative Advantages merupakan tingkat kelebihan suatu inovasi, apakah lebih baik dari inovasi yang ada sebelumnya atau dari hal-hal yang biasa dilakukan (Chemingui dan Hajer, 2013). Personal Innovativeness merupakan persepsi sejauh mana pengguna sistem percaya bahwa sistem tersebut memiliki unsur kebaruan dan keunikan (Amoroso dan Ricardo, 2015), sedangkan Cost merupakan biaya yang ditimbukan dari pengadopsian sebuah teknologi, semakin tinggi biaya yang ditimbulkan membuat teknologi akan sulit untuk diterima (Yao et al, 2013).

\section{PENELITIAN TERDAHULU}

Penelitian tentang hubungan antara Mobile Banking dan Usaha Mikro, Kecil, dan Menengah (UMKM) semakin berkembang dalam beberapa tahun terakhir. Onyango meneliti dampak adopsi dan penggunaan teknologi ponsel pada kinerja usaha mikro dan kecil, dan menunjukkan hubungan positif antara penggunaan teknologi ponsel dan kinerja usaha mikro dan kecil (Onyango et al, 2014). Demikian pula, Kakwa mengemukakan bahwa terdapat pengaruh adopsi dan penggunaan teknologi ponsel di Usaha Mikro, Kecil, dan Menengah (UMKM) yang lebih cepat terhadap kebutuhan pelanggan, peningkatan efisiensi internal, akses ke pasar baru, dengan biaya operasional yang lebih rendah (Kakwa,2012). Simiyu dan Oloko menemukan bahwa ketersediaan transaksi pada Mobile Money memperluas basis pelanggan Usaha 
Mikro, Kecil, dan Menengah (UMKM), dimana faktor aksesibilitas, kenyamanan, dan biaya yang lebih rendah dari sifat transaksi seluler meningkatkan pertumbuhan kegiatan Usaha Mikro, Kecil, dan Menengah (UMKM) terutama di daerah pedesaan (Simiyu dan Oloko, 2015).

Beberapa penelitian lainnya juga menemukan bahwa penggunaan layanan Mobile Banking atau mobile money dapat meningkatkan performa UMKM dalam hal pertumbuhan penjualan, pangsa pasar dan profitabilitas (Wanyonyi dan Bwisa, 2013) (Kirui dan Onyuma, 2015), (Mararo dan Ngahu, 2017). Nyaga dan Okonga menemukan bahwa transaksi mobile money meningkatkan kinerja UMKM (Nyaga dan Okonga, 2014), hal ini didukung oleh penelitian Kirui dan Onyuma yang menemukan bahwa transaksi mobile money memudahkan cara pembayaran dan tanda terima dibuat, serta meningkatkan kinerja UKM karena menghemat waktu, menghemat biaya serta fleksibel mengingat bahwa transaksi dapat dilakukan di mana saja pada waktu tertentu (Kirui dan Onyuma, 2015). Masocha menemukan bahwa, layanan mobile money memberikan dampak signifikan terhadap performa pada berbagai jenis Usaha Mikro, Kecil, dan Menengah (Masocha dan Obey, 2018). Selain itu layanan Mobile Banking dapat membantu UMKM dalam mengakses kredit melalui pembiayaan seluler dan membantu mereka memenuhi kebutuhan bisnis jangka pendek (Mararo dan Ngahu, 2017).

\section{METODE PENELITIAN}

Pengamatan pada penelitian ini hanya dilakukan sekali waktu sesuai yang telah ditentukan (Cross Sectional), selain itu penelitian ini juga akan melihat adanya hubungan antara variabel dependen dan variabel independen (Sugiyono, 2013). Riset ini merupakan jenis penelitian kuantitatif. Populasi didalam penelitian ini adalah pelaku UMKM yang menggunakan Mobile Banking di Kota Makassar. Penarikan sampel dalam penelitian ini menggungakan metode Purposive Sampling, yaitu teknik pengambilan sampel sumber data dengan pertimbangan tertentu oleh peneliti (Sugiyono, 2013). Metode purposive sampling didasarkan pertimbangan pada pelaku UMKM di Kota Makassar yang menggunakan Mobile Banking minimal satu tahun terakhir, pertimbangan ini diambil dengan harapan responden dapat memahami perkembangan kegiatan usaha yang dijalankan berdasarakan pengalaman selama menggunakan layanan Mobile Banking.

Variabel Independen dalam penelitian adalah Technology Acceptance Model (TAM) yang diadaptasi dari literatur dan penelitian sebelumnya yaitu Perceived Ease of Use, Perceived Usefulness, Social Norms, Perceived Risk, Relative Advantages, Personal Innovativeness dan Cost (Chitungo dan Munongo, 2013), dan Performa UMKM (Mararo dan Ngahu, 2017). sebagai Variabel Dependen. Instrumen pengumpulan data pada penelitian ini menggunakan kuesioner. Pengujian instrumen penelitian (Uji Validitas dan Uji Realibilitas), Uji parsial (uji T), Uji simultan (uji F), dan Multiple Regression Analysis dilakukan menggunakan Software Statistical Package for the Social Sciences (SPSS).

\section{HASIL DAN PEMBAHASAN}

Penelitian bertujuan untuk menguji Technology Acceptance Model (TAM) penggunaan Mobile Banking dalam menunjang usaha UMKM di Kota Makassar. Pengumpulan data dari sampel penelitian melalui penyebaran kuesioner berhasil mengumpulkan data responden pelaku industri UMKM sebanyak 278 orang. 
Gambar 1. Model Penelitian

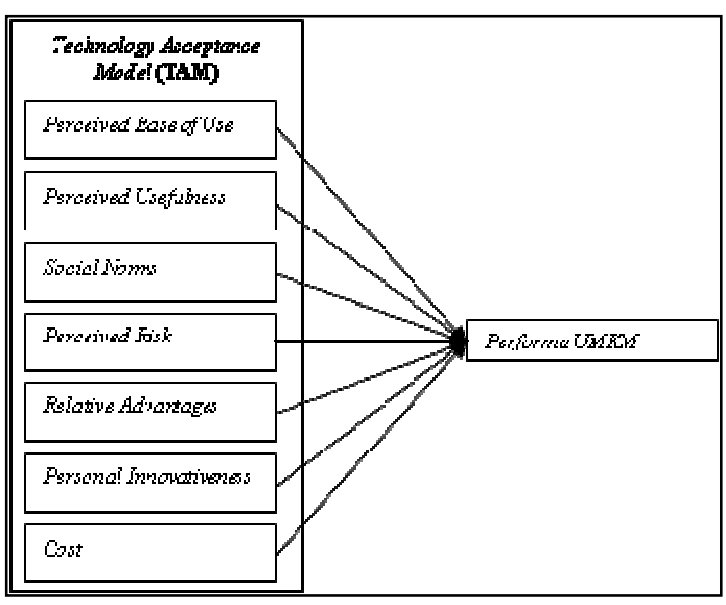

\section{Karekteristik Responden}

Data responden dikumpulkan dan dikelompokkan berdasarkan karaktersitik masing-masing. Dari total 278 responden sebanyak 67\% berjenis kelamin Pria dan sisanya sebanyak $33 \%$ berjenis kelamin Perempuan. Berdasarkan jenjang pendidikan sebanyak 7\% reponden berpendidikan setara Sekolah Dasar, 17\% responden berpendidikan setara Sekolah Menengah Pertama (SMP), 19\% responden berpendidikan setara Sekolah Menengah Atas (SMA), $48 \%$ responden berpendidikan setara Sarjana, dan sebanyak 9\% responden berpendidikan Pascasarajana. Sedangkan untuk sektor UMKM yang menjadi sampel penelitian sebanyak 54\% bergerak pada sektor Perdagangan, 46\% bergerak pada sektor Industri dan Pengolahan, 8\% bergerak pada sektor Pertanian, 17\% bergerak pada sektor Perkebunan, 6\% bergerak pada sektor Peternakan, 2\% bergerak pada sektor Perikanan dan 12\% respoden bergerak pada sektor Jasa. Penelitian ini juga mengelompokkan responden beradasarkan lama UMKM menggunakan layanan Mobile Banking, berdasarkan data yang terkumpul sebanyak $26 \%$ responden telah menggunakan Mobile Banking kurang dari 1 tahun, 41\% telah telah menggunakan Mobile Banking selama 1 sampai 3 tahun, $28 \%$ responden telah menggunakan Mobile Banking selama 3 sampai 6 tahun, dan 5\% responden telah menggunakan Mobile Banking selama 6 tahun lebih. Selain data diatas penelitian ini mengelompokkan responden berdasarkan Omzet UMKM yang diperoleh setiap tahunnya. Berdasarkan data yang terkumpul sebanyak $35 \%$ responden berpenghasilan kurang dari 100 juta setiap tahunnya, $28 \%$ responden berpenghasilan 100 sampai 300 juta setiap tahunnya, 21\% responden berpenghasilan 300 sampai 600 juta setiap tahunnya, 15\% responden berpenghasilan 600 juta sampai 1 miliar setiap tahunnya, dan sisanya sebanyak $2 \%$ responden berpenghasilan diatas 1 miliar setiap tahunnya.

\section{Analisis Data}

Uji validitas dilakukan untuk menguji item indikator dalam mewakili konstruk yang digunakan dalam penelitian ini, pengujian item dilakukan dengan menghitung nilai $r$ hitung dan membandingkannya dengan nilai $r$ tabel. Berdasarkan uji validitas diperoleh hasil bahwa dari 17 item pertanyaan tidak ditemukan satupun yang memiliki nilai $r$ hitung lebih kecil dari $r$ tabel dengan derajat kebebasan $(\mathrm{df}=\mathrm{N}-2)$ 276 sebesar 0,099.

Uji Reliabilitas dilakukan untuk menguji sejauh mana pengukuran dari setiap item tetap konsisten dalam mewakili konstruk dalam penelitian ini, sehingga setiap indikator dianggap dapat diandalkan dan konsisten dalam mengukur konstruk penelitian, pengujian dilakukan dengan membandingkan nilai cronbach alpha dari setiap item dengan ketentuan nilai cronbach alpha tersebut $\geq 0,6$. Nilai cronbach alpha dari setiap konstruk dalam penelitian ini dapat dilihat pada tabel 1 .

Tabel.1 Nilai Cronbach Alpha

\begin{tabular}{|l|c|c|}
\hline \multicolumn{1}{|c|}{ Variabel } & $\begin{array}{c}\text { Cronbach } \\
\text { Alpha }\end{array}$ & Keterangan \\
\hline Perceived Ease of Use & 0,604 & Reliabel \\
Perceived Usefulness & 0,745 & Reliabel \\
Social Norms & 0,905 & Reliabel \\
Perceived Risk & 0,815 & Reliabel \\
\hline
\end{tabular}




\begin{tabular}{|l|l|l|}
\hline Relative Advantages & 0,635 & Reliabel \\
Personal Innovativeness & 0,845 & Reliabel \\
Cost & 0,735 & Reliabel \\
Performa UMKM & 0,875 & Reliabel \\
\hline
\end{tabular}

Berdasarkan nilai cronbach alpha dari berbagai konstruk yang ada dapat disimpulkan bahwa seluruh item dalam penelitian ini dinyatakan reliabel untuk digunakan.

Koefisien determinasi berdasarkan dari output pada tabel Model Summary nilai $R$ Square menunjukkan nilai sebesar 0,568 yang berarti seluruh konstruk yang ada dalam model penelitian dapat menerangkan perubahan pada variabel dependen sebesar $56,8 \%$ dan sisanya sebesar $43,2 \%$ dipengaruhi oleh variabel lain yang tidak dimasukkan dalam penelitian ini.

Analisis data dilakukan dengan menggunakan Multiple Regression Analysis untuk menguji pengaruh variabel independen terhadap variabel Dependen yang terdiri dari Perceived Ease of Use, Perceived Usefulness, Social Norms, Perceived Risk, Relative Advantages, Personal Innovativeness dan Cost terhadap variabel dependen yaitu performa UMKM.

Tabel 2. Nilai Coefficient

\begin{tabular}{|c|c|c|c|c|c|}
\hline \multirow[b]{2}{*}{ Model } & \multicolumn{2}{|c|}{$\begin{array}{l}\text { Unstandardized } \\
\text { Coefficients } \\
\end{array}$} & \multirow{2}{*}{\begin{tabular}{|c|}
$\begin{array}{c}\text { Standardized } \\
\text { Coefficients }\end{array}$ \\
Beta \\
\end{tabular}} & \multirow[t]{2}{*}{$t$} & \multirow[t]{2}{*}{ Sig. } \\
\hline & B & Std. Error & & & \\
\hline 1 (Constant) & 3.844 & .820 & & 4.689 & .000 \\
\hline Perceived Ease of Use & .192 & .077 & .124 & 2.503 & 013 \\
\hline Perceived Usefulness & .280 & .057 & .371 & 3.403 & .002 \\
\hline $\begin{array}{l}\text { Social Norms } \\
\text { Perceived Risk }\end{array}$ & $\begin{array}{l}.137 \\
.122\end{array}$ & $\begin{array}{l}.040 \\
.031\end{array}$ & $\begin{array}{l}.243 \\
.231\end{array}$ & $\begin{array}{l}2.916 \\
2.881\end{array}$ & .000 \\
\hline Relative Advantages & .215 & .051 & .206 & 4.205 & .000 \\
\hline Personal Innovativeness & .570 & .064 & .484 & 8.911 & .000 \\
\hline Cost & .142 & .066 & .112 & 2.153 & .032 \\
\hline
\end{tabular}

Regression Analysis menunjukkan bahwa seluruh variabel Independen berpengaruh signifikan terhadap variabel Dependen yaitu performa UMKM dimana diperoleh persamaan regresi sebagai berikut:

$$
\begin{aligned}
\mathrm{Y}= & 3.844+0.192 \mathrm{X}_{1}+0.280 \mathrm{X}_{2}+\mathrm{0.137}_{3}+ \\
& \mathbf{0 . 1 2 2}_{4}+0.215 \mathrm{X}_{5}+0.570 \mathrm{X}_{6}+0.142 \mathrm{X}_{7}
\end{aligned}
$$

Persamaan regresi tersebut menunjukkan bahwa nilai konstanta positif sebesar 3.844 yang berarti bahwa apabila variabel-variabel dependen diasumsikan konstan maka variabel performa UMKM mengalami kenaikan sebesar 3.844.

Selanjutnya untuk seluruh variabelvariabel independen memiliki nilai koefisien positif yang berarti seluruh variabel independen berpengaruh positif terhadap variabel dependen antara lain variabel Perceived Ease of Use ( $\left.\mathrm{X}_{1}\right)$ memiliki nilai koefisien regresi positif sebesar 0.192, variabel Perceived Usefulness $\left(\mathrm{X}_{2}\right)$ memiliki nilai koefisien positif sebesar 0.280 , variabel Social Norms $\left(\mathrm{X}_{3}\right)$ yang memiliki nilai koefisien positif sebesar 0.137, variabel Perceived Risk $\left(\mathrm{X}_{4}\right)$ memiliki nilai koefisien positif 0.215 , variabel Relative Advantages $\left(\mathrm{X}_{5}\right)$ memiliki nilai koefisien positif sebesar 0.215, variabel Personal Innovativeness $\left(\mathrm{X}_{6}\right)$ memiliki nilai koefisien positif sebesar 0.570 dan variabel Cost $\left(\mathrm{X}_{7}\right)$ memiliki nilai koefisien positif sebesar 0.142 .

Uji $F$ dilakukan untuk melihat pengaruh keselunuhan variabel independen terhadap variabel dependen secara bersamaan (simultan). Pengujian dilakukan dengan membandingkan nilai $\mathrm{F}$ hitung dengan nilai $F$ tabel. Hasil analisis menunjukkan bahwa nilai $\mathrm{F}$ hitung lebih besar dari pada nilai $F$ tabel. Dalam tabel $\mathrm{F}$ dengan probabilita 0.05 dimana degree of freedom (df) pembilang $6(\mathrm{k}-1)$ dan degree of freedom (df) penyebut $271(\mathrm{n}-\mathrm{k})$ diperoleh nilai $F$ tabel sebesar 2,1321 selanjutnya berdasarkan perhitungan output hasil olah data diperoleh nilai $F$ hitung sebesar 33.704, hal ini berarti bahwa nilai $\mathrm{F}$ hitung lebih besar dari $\mathrm{F}$ tabel maka dapat disimpulkan bahwa variabel indepdenden yang ada dalam penelitian ini yang terdiri dari Perceived Ease of Use, Perceived Usefulness, Social Norms, Perceived Risk, Relative Advantages, Personal Innovativeness dan 
Cost secara simultan berpengaruh signifikan terhadap variabel dependen yaitu Performa UMKM.

Uji $\mathrm{T}$ dilakukan melihat pengaruh variabel independen terhadap variabel dependen secara terpisah (parsial). Uji dilakukan dengan membandingkan nilai $\mathrm{t}$ hitung dengan nilai t tabel. Menggunakan tabel $\mathrm{t}$ dengan probabilita 0.05 dengan degree of freedom (df) 271 diperoleh nilai t tabel sebesar 1,9687. Berdasarkan hasil perhitungan $\mathrm{t}$ hitung variabel independen Perceived Ease of Use sebesar 2.503, variabel Perceived Usefulness sebesar 3.403, variabel Social Norms sebesar 2.916, variabel Perceived Risk sebesar 2.881, variabel Relative Advantages sebesar 4.205, variabel Personal Innovativeness sebesar 8.911dan variabel Cost sebesar 2.153. Berdasarkan hasil tersebut dapat disimpulkan Technology Acceptance Model yang meliputi Perceived Ease of Use, Perceived Usefulness, Social Norms, Perceived Risk, Relative Advantages, Personal Innovativeness dan Cost memiliki nilai $\mathrm{t}$ hitung yang lebih besar dari $t$ tabel dengan signifikansi lebih kecil dari 0.05 yang berarti secara parsial berpengaruh signifikan terhadap variabel dependen yaitu Performa UMKM.

\section{Pembahasan}

1) Hasil penelitian menunjukkan bahwa terdapat pengaruh positif dan signifikan dari variabel Independen yaitu Technology Acceptance Model yang meliputi Perceived Ease of Use, Perceived Usefulness, Social Norms, Perceived Risk, Relative Advantages, Personal Innovativeness dan Cost terhadap variabel Dependen Performa UMKM baik secara parsial maupun secara simultan.

2) Secara parsial variabel Perceived Ease of Use $\left(\mathrm{X}_{1}\right)$ berpengaruh positif dan signifikan terhadap performa UMKM di Kota Makassar, dapat disimpulkan bahwa para pelaku bisnis khususnya
UMKM dikota Makassar merasakan manfaat penggunaan Mobile Banking mampu meringankan dalam mengelola bisnisnya.

3) Secara parsial variabel Perceived Usefulness $\left(\mathrm{X}_{2}\right)$ berpengaruh positif signifikan terhadap performa UMKM di Kota Makassar, yang menindikasikan bahwa penggunaan Mobile Banking dianggap dapat meingkatkan kinerja dan profitabilitas UMKM

4) Secara parsial variabel Social Norms $\left(\mathrm{X}_{3}\right)$ berpengaruh positif dan signifikan terhadap performa UMKM di Kota Makassar, dimana dengan menggunakan Mobile Banking akan mampu meningkatkan citra dan profesionalitas pengeolalaan bisnis UMKM di Kota Makassar baik dimata konsumen maupun pesaing bisnis.

5) Secara parsial variabel Perceived Risk $\left(\mathrm{X}_{4}\right)$ berpengaruh positif dan signifikan terhadap perfoma UMKM di Kota Makassar, hal ini berarti bahwa para pelaku bisnis UMKM menganggap bahwa penggunaan Mobile Banking dapat mengurangi resiko bisnis yang dihadapi para pelaku bisnis UMKM di Kota Makassar.

6) Secara parsial variabel Relative Advantages $\left(\mathrm{X}_{5}\right)$ berpengaruh positif dan signifikan terhadap performa UMKM di Kota Makassar, para pelaku UMKM di Kota Makassar menganggap penggunaan UMKM dapat menjadi keunggulan tersendiri pada pengelolaan bisnis mereka baik dalam hal melayani pelanggan maupun menghadapi para pesaing usaha lainnya.

7) Secara parsial variabel Personal Innovativeness $\left(\mathrm{X}_{5}\right)$ berpengaruh positif dan signifikan terhadap perfoma UMKM di Kota Makassar, para pelaku UMKM di Kota Makassar beranggapan bahwa penggunaan Mobile Banking merupakan 
sebuah inovasi yang baru yang belum perbah ada sebelumnya dan bukan merupakan sesuatu yang pernah terbayangkan sebelumnya.

8) Secara parsial variabel Cost $\left(\mathrm{X}_{7}\right)$ berpengaruh positif dan signifikan terhadap performa UMKM di kota Makassar, hal ini berarti para pelaku UMKM di Kota Makassar menganggap penggunaan Mobile Banking dapat membantu mengurangi biaya dan meningkatkan efesiensi pengelolaan keuangan dan bisnis.

\section{KESIMPULAN}

Berdasarkan hasil pengolahan data penelitian ditemukan bahwa semua indikator yang membangun konstruk Technology Acceptance Model pada Mobile Banking yang terdiri dari Perceived Ease of Use, Perceived Usefulness, Social Norms, Perceived Risk, Relative Advantages, Personal Innovativeness dan Cost berpengaruh dalam menunjang performa UMKM. Melalui penggunaan teknologi Mobile Banking dapat menjadi pemicu peningkatan kinerja bisnis UMKM dalam menghadapi persaingan usaha di era digital saat ini diharapkan melalui teknologi ini dapat menjadi salah satu penunjang usaha khususnya yang berskala Usaha Mikro, Kecil, dan Menengah (UMKM) dimasa yang akan datang.

\section{SARAN}

Penelitian ini dilakukan dan melibatkan 278 orang responen yang terlibat dalam industri Usaha Mikro, Kecil, dan Menengah di Kota Makassar hasil penelitian dapat berbeda dengan melibatkan jumlah responden dengan skala yang lebih besar da cakupan wilayah dan dimensi yang lebih luas, perluasan kajian dan subyek penelitian sangat memungkinkan dalam mengkaji hasil penelitian lebiih jauh lagi. Berbagai desain penelitian juga masih sangat memungkinkan dalam mengkaji topik Technology Acceptance Model serta dampaknya pada performa UMKM, misalnya dengan penggunaan desain penelitian eksperimen dengan topik serupa.

Hasil penelitian ini dapat menjadi masukan bagi pihak yang berkepentingan dalam merumuskan kebijakan terkait implementasi Mobile Banking serta kaitanya terhadap Usaha Mikro, Kecil, dan Menengah (UMKM) di Indonesia khususnya di Kota Makassar, dimana tuntutan jaman akan perubahan ke era digital yang lebih dinamis memerlukan kebijakan dan edukasi secara komprehensif.

\section{TERIMA KASIH}

Penulis menyampaikan terima kasih pada seluruh pihak yang berpartisipasi dan mendukung terlaksananya penelitian baik kepada para responden dan dinas terkait penelitian ini terkhusus kepada Kementerian Riset, Teknologi dan Pendidikan Tinggi yang memberikan pendanaan pada penelitian ini melalui skema Penelitian Dosen Pemula tahun anggaran 2019.

\section{DAFTAR PUSTAKA}

Lembaga Pengembangan Perbankan Indonesia. 2015. Profil Bisnis Usaha Mikro, Kecil dan Menengah (UMKM). Jakarta: Bank Indonesia.

Hamzah. 2018. Selama 3 Tahun, Dinas Koperasi Kota Makassar Catat 16.428 UKM Baru. Portal Makassar (internet). (diakses 19 Agustus 2018). Tersedia pada: https://www.portalmakassar.com/se lama-3-tahun-dinas-koperasi-kotamakassar-catat-16-428-ukm-baru/.

Mararo, M.W. dan Ngahu, S. 2017. Influence of mobile money services on the growth of SME in Nakuru town, Kenya. Journal of Humanities and Social Science, 22(10), 64-72. 
Sledzik, Karol. 2013. Schumpeter's View on Innovation and Entrepreneurship. Management Trends in Theory and Practice. Faculty of Management Science and Informatics, University of Zilina \& Institute of Management by University of Zilina.

Otoritas Jasa Keuangan. 2015. Bijak Ber e-Banking (e-book), Otoritas Jasa Keuangan: Jakarta.

Lule, Isaiah, Omwansa, Tonny Kerage dan Waema, Timothy Mwololo. 2012. Application of Technology Acceptance Model (TAM) in MBanking Adoption in Kenya. International Journal of Computing and ICT Research. Vol. 6 Issue 1, pp 31-43.

Chitungo, Shallone K, dan Munongo, Simon. 2013. Extending the Technology Acceptance Model to Mobile Banking Adoption in Rural Zimbabwe. Journal of Business Administration and Education. 3 (1), 51-79.

Reich, Blaize Horner and Izak Benbasat. 2000. Factors That Influence the Social Dimension of Alignment Between Business and Information Technology Objectives. MIS Quarterly; Mar 2000;24, 1; ABI/INFORM Global pg. 81.

Pedersen, P. dan Ling, R. 2002. Modifying adoption research for mobile internet service adoption: Crossdisciplinary interactions. Proceedings of the 36th Hawaii International Conference on System Sciences, Big Island, HI, January 6-9.

Fadare OA. 2016. A Survey on Perceived Risk and Intention of Adopting Internet Banking. Journal of
Internet Banking and Commerce. April 2016, vol. 21, no. 1.

Chemingui, Hella and Hajer Ben lallouna. 2013. Resistance, motivations, trust and intention to use mobile financial services. International Journal of Bank Marketing, Vol. 31 Issue: 7, pp.574-592.

Amoroso, Donald L dan Ricardo A. Lim. 2015. Exploring the Personal Innovativeness Construct: The Roles of Ease of Use, Satisfaction and Attitudes. Asia Pacific Journal of Information Systems 25 No. 4 (December 2015), 662-685.

Yao, Huili, Liu, Shanzhi, dan Yuan, Yinghui. 2013. A Study of User Adoption Factors of Mobile Banking Services Based onthe Trust and Distrust Perspective. International Business and Management. 6(2), 9-14.

Onyango, R., Ongus, R., Awuor, F., dan Nyamboga, C. 2014. Impact of Adoption and Use of Mobile Phone Technology on The Performance of Micro and Small Enterprises in Kisii Municipality Kenya. World Journal of Computer Application and Technology, 2(2): 34-42.

Kakwa, A. 2012. Mobile Phone Usage by Micro and Small Scale Enterprises in Semi-Rural Ghana. International Review of Management and Marketing 2(3): 156-164.

Simiyu, C.N. dan Oloko, M. 2015. Mobile Money Transfer and The Growth of Small and Medium Sized Enterprises in Kenya: A case of Kisumu city, Kenya. International Journal of Economics, Commerce and Management, 3(5), 1056-1065. 
Wanyonyi, P.W. dan Bwisa, H.M. 2013. Influence of Mobile Money Transfer Services on The Performance of Micro Enterprises in Kitale Municipality. International Journal of Academic Research in Business and Social Sciences, 3(5), 500-517.

Kirui, R.K. dan Onyuma, S.O. 2015. Role of Mobile Money Transactions on Revenue of Microbusiness in Kenya. European Journal of Business and Management, 7(36), 63-67.

Nyaga, K.M. dan Okonga, B.M. 2014. Does mobile money services have an impact on SMEs performance in Naivasha? International Journal of Current Research, 6(10), 93949398.

Masocha, Reginald dan Obey Dzomonda. 2018. Adoption of Mobile Money Services and The Performance of Small and Medium Enterprises in Zimbabwe. Academy of Accounting and Financial Studies Journal. Volume 22, Issue 3.

Sugiyono. 2013. Metodelogi Penelitian Kuantitatif, Kualitatif dan R\&D. Bandung: Alfabeta. 